\title{
EL CORREO CARLISTA EN EL MAESTRAZGO \\ (1872-1875)
}

\section{THE CARLIST MAIL IN THE MAESTRAZGO (1872-1875)}

\section{Gerhard Lang-Valchs}

\section{RESUMEN}

El presente artículo describe el sistema del correo en el Maestrazgo organizado por los insurgentes durante la última de las Guerras Carlistas (1872-1876). Incluye también, además de los aspectos de administración postal, algunos filatélicos referentes a los sellos allí usados, basándose mayormente en un mapa postal carlista olvidado y los documentos del archivo de la familia Borbón-Parma.

Palabras clave: Carlismo, filatelia, Maestrazgo

\begin{abstract}
The present article describes the organisation of the postal system at the Spanish Maestrazgo-region (provinces of Valencia, Castellón, Teruel) established by the insurgents during the last Carlist War in Spain (1872-1876). Beside the aspects of the postal administration it takes in account as well some philatelic ones concerning the use of the stamps supposedly issued there. The study is mainly based on a forgotten carlist post route map and the documents accessible at the archive of the Borbón-Parma family.
\end{abstract}

Keywords: Carlism, philatelic, Maestrazgo 


\section{RESUM}

\section{El correu carlista en el Maestrazgo (1872-1875)}

Aquest article descriu el sistema de correus al Maestrat organitzat pels carlins durant la darrera guerra (1872-1876). Inclou també, a més dels aspectes d'administració postal, alguns filatèlics referents als segells utilitzats basant-nos majoritàriament en un

mapa postal carlí oblidat i als documents de l'arxiu de la família Borbón-Parma.

Paraules clau: Carlisme, filatèlia, Maestrat 
De todo lo escrito sobre la última Guerra Carlista (1872-1876), la zona del Maestrazgo es la que menos ha atraído la atención de los investigadores. ${ }^{\prime}$ Existen varias publicaciones sobre el correo durante las contiendas provocadas por las insurrecciones carlistas entre las que la organización del correo en País Vasco y Navarra se lleva, por cierto, la palma en cuanto al número. Pero dentro de este ámbito no hay ninguna obra que se dedique exclusivamente a nuestro tema. La administración de Correos allí crea- da llegó a funcionar durante más de dos años con notable eficacia y hasta con una "estafeta inoficial" en Francia lo que generó documentos de toda clase, lo que invita a su estudio. ${ }^{2}$

Bastante menos se ha publicado sobre el correo carlista de Cataluña, debido a la escasez de documentación. Y, que se sepa, el correo carlista del Maestrazgo se menciona por las mismas razones tan sólo en un reducido apartado de algún artículo generalista sobre el correo de los insurgentes. ${ }^{3}$

La situación del correo en el Maestrazgo es un reflejo de la situación militar y administrativa en la zona controlada por los carlistas en aquellos años. Al mando de cabecillas como Ramón Cabrera o Pascual Cucala ocupaban con sus seguidores pueblos para establecer desde allí y en las zonas colindantes su dominio y así poder llevar a cabo sus acciones bélicas, que les llevaban a veces lejos de su punto de partida, desde su base en un sitio relati-

1 Véase la bibliografía al final del artículo. No es éste el lugar de discutir si hay que incluir o no la Guerra dels Matiners (1846-1849) en este recuento y hablar de dos o de tres guerras. Hablaremos de la última Guerra Carlista refiriéndonos a la de 1872-1876.

2 ESCALADA, E. (2000): La organización del correo carlista (1873-1876), Academia Hispánica de la Filatelia, Madrid. El autor enfoca principalmente la zona del País Vasco y Navarra.

3 Lo más consistente, aparte de lo arriba citado, se encuentra en una página y media de un librito de IGLESIAS, L.: Numismática y filatelia del carlismo, Boletín de Estudios Históricos sobre San Sebastián, $n^{\circ} 42$ [Separata], San Sebastián 2008-2009, p. 236-237. La falta de citas, sin embargo, no da opción a contrastar algunas informaciones potencialmente interesantes que no coinciden con los datos en los que se basa el presente artículo. 
vamente seguro. En esta guerra de guerrillas sin frentes ni fronteras claras apenas había una coordinación entre las diferentes facciones. Cada uno de los líderes locales hacía su propia guerra y no se sometía, en la práctica, al mando del Ejército de Cataluña y Valencia y de su representante al que teóricamente pertenecía.

Esta falta de coordinación y planificación se iba lógicamente notando también en el campo de la administración civil que poco a poco dejó de cumplir sus funciones, servicio de correo incluido. Durante algún tiempo y en algunas partes del territorio dominado hubo hasta tres servicios postales paralelos: el estatal, el carlista militar y el carlista civil. Hay muy pocos documentos o noticias sobre la situación administrativa durante la contienda. Aparte de noticias cortas y muy dispersas en algún que otro periódico $\circ$ alguna mención, por regla general poco crítica y sin documentar, disponemos de algunos mapas postales oficiales inmediatamente anteriores o posteriores a la guerra, de un mapa postal carlista, ${ }^{4}$ también de una memoria del ministro de la Gobernación, ${ }^{5}$ de un libro que nos ha conservado unos decretos con disposiciones del general carlista Dorregaray, ${ }^{6}$ así como de la correspondencia y otros documentos conservados en el archivo de la famila Borbón-Parma. ${ }^{7}$

\section{El correo estatal}

La insurrección carlista del Maestrazgo no condujo, como en el Norte, al colapso casi inmediato de la administración civil y con ella también a la de los servicios de Correos. De esta forma se produjo una rápida creación de un servicio postal propio que, ya a principios de 1874, funcionaba plenamente. En la primera fase de la guerra hasta mediados de 1874 en la zona del Centro, como se llamaba oficialmente este territorio, la situación postal tuvo que ser parecida a la descrita para el pueblo conquense de Cañete, ubicado no muy lejos de la zona que enfocamos. ${ }^{8} \mathrm{~A}$ pesar de tener una pequeña guarnición car-

4 Mapa de Correos de la zona de Castellón trazado por los carlistas..., Museo postal [MP], Legado Thebusem [LT], BMPT A-5 5(8) R.6026.

5 Memoria presentada el 2 de enero de 1874 a las Cortes Constituyentes por el ministro de la Gobernación D. Eleuterio Maisonnave (1874), Imprenta Nacional, Madrid.

6 OLIVER, A. (1876): Dorregaray y la traición del centro: Apuntes para la historia de la última guerra civil, Bayona.

7 Archivo Histórico Nacional [AHN], Fondo de la familia Borbón-Parma [BP], en parte digitalizado y accesible por internet.

8 Cuerpo del Estado Mayor del Ejército: Narración de la Guerra Carlista de 1869 a 1876, (1889) tomo XIV, Madrid, p. 202. 
lista permanente, el correo estatal seguía funcionando. Los rebeldes toleraban el servicio y se servirían en más de una ocasión de sus ventajas, aunque ciertamente no para fines militares y revolucionarios, y dejaban que también la población siguiera disfrutando igualmente de él. Esto tuvo que ser la tónica general en gran parte de la zona puesto que la ya citada Memoria no habla, a pesar de mencionar algunos problemas puntuales, de ninguna situación difícil o alarmante en cuanto al suministro de correo hacia finales del año 1873. ${ }^{9}$

Todo esto tenía su lógica. Por un lado los insurgentes no tenían instalado ni previsto todavía un correo propio en esta zona, sólo disponían de su correo militar, que por razones obvias, no querían poner, ni siquiera de forma camuflada, en manos civiles o de funcionarios no necesariamente afectos a su causa. Así que la correspondencia privada y comercial dentro de la zona rebelde y hacia fuera estaba asegurada mientras que el gobierno central a través de la Dirección de Correos no retirara este servicio y esto no solía ocurrir siempre que los funcionarios y carteros no fueran molestados, agredidos o detenidos por los carlistas.
Las acciones militares carlistas pretendían asegurar el dominio de su zona inicial de influencia, principalmente rural, y extenderlo a los centros urbanos, aislar y conquistar finalmente también las ciudades con Madrid como meta final. Por esto los rebeldes empezaron a interrumpir y destruir parte de la red telegráfica sobre todo en los tramos que unían Madrid con las capitales de provincia. También las comunicaciones a larga distancia como los trenes-correo se convirtieron en objetivo preferido de los ataques tanto en Cataluña como en el Centro.

La situación se agravó con la creación de una administración postal carlista para Cataluña en primavera de 1874. A través de diferentes decretos tanto la administración estatal -referiéndose a todas las zonas en rebeldía- como la carlista catalana prohibieron a sus funcionarios admitir el uso de los sellos postales del lado opuesto, la conducción de correspondencia sin franquear o franqueada con sellos de ambos lados a la vez. ${ }^{10}$ Esto implicó el final del suministro de la zona insurgente por el correo estatal y al hostigamiento de los carteros carlistas por las fuerzas liberales.

La zona del Maestrazgo era atrave-

9 OLCINA, E. (1974): El Carlismo y las autonomías regionales, Seminarios y Ediciones, p. 52 es de la misma opinión. La falta de referencias impide saber en qué documentos se basa. Memoria, p. $210-211$.

10 PEÑA, J. (2005): Los sellos carlistas de Cataluña. Contexto histórico, Colección: Monografías Filatélicas de Afinet $n^{\circ} 7$, Barcelona 
sada cerca del litoral por la línea férrea que transportaba la correspondencia de Murcia, Alicante y Valencia vía Castellón y Tarragona a Barcelona y desde allí a Francia. El hostigamiento de los trenes-correo por los carlistas tuvo sus efectos. La conducción ferroviaria llegó a pararse, pero, según los criterios de Correos, recurriendo a diligencias y a veces a la vía marítima se podía salvar razonablemente bien la situación. Así, aunque en un principio se barajó como vía alternativa, finalmente no se adoptó una conducción continuada por barco entre Valencia, Tarragona y Barcelona.

La comparación de los mapas postales de 1871 y 1877 con el mapa carlista [Figura 1] deja patente la falta de conexiones postales transversales a través del Maestrazgo durante los años de la guerra así como la interrupción del suministro de puntos importantes de distribución como Morella y Lucena normalmente servidos desde Castellón que no estaba en manos de los rebeldes. Quedó afectada también la conducción por diligencia entre las capitales Valencia y Teruel vía Segorbe y Sarrión, cosa que, sin embargo, apenas podría afectar al suministro de la zona.

\section{EL CORREO MILITAR}

Sobre la estructura del correo militar y sobre su funcionamiento sabemos muy poco. Se tuvo que adaptar, como es natural, a las necesidades de la guerra y de las partidas. A pesar de su confusa estructura debido a la guerra de guerrillas y la consiguiente falta de una organización militar convencional, su servicio fue por lo visto satisfactorio. En gran parte asumió las tareas del correo estatal cuando éste dejó de funcionar. Prueba de su eficacia es su uso para fines privados y comerciales, lo que provocó, sin embargo, una sobrecarga y ralentización del servicio. Es precisamente este abuso lo que Dorregaray prohíbe expresamente en su decreto de febrero de 1875. Quiere ver separados claramente ambos servicios sancionando severamente su incumplimiento. ${ }^{11}$

Al trazar las líneas de su reorganización postal militar Dorregaray se basa en las administraciones militares, ya creadas o por crear, que parecen coincidir con los seis antiguos distritos de la zona.

\section{El MAPA DEL CORREO CARLISTA}

El mapa postal carlista del que disponemos es una copia (Figura 1). El mapa original estaba entre los documentos incautados por las tropas

11 OLIVER: Dorregaray, p. 104-106. 


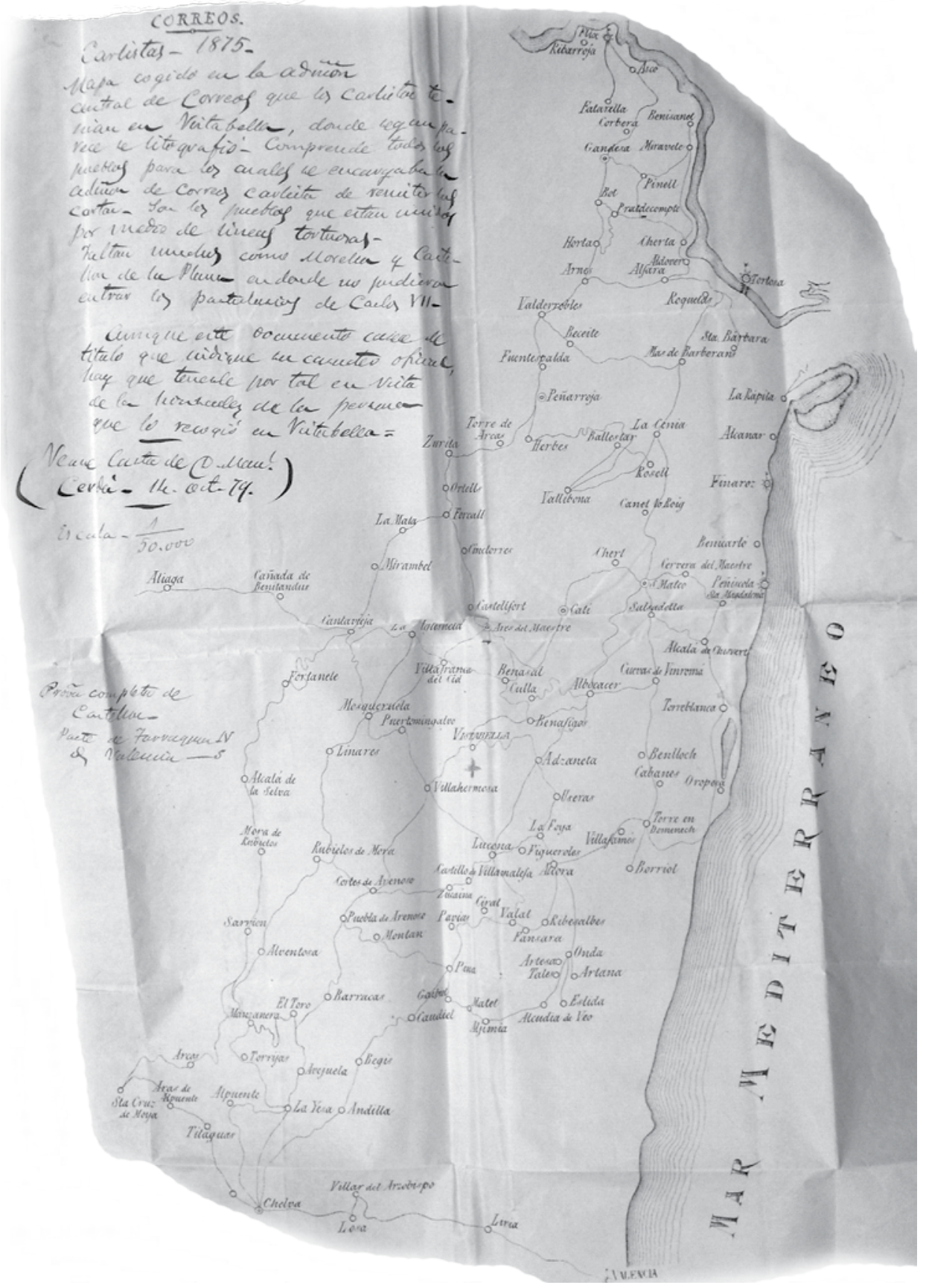

Fig.- 1. Mapa del correo carlista. 
liberales con motivo de la conquista del bastión carlista de Vistabella en 1875. El fondo al que pertenece, si es que existe todavía, se encuentra probablemente en el Archivo Histórico Militar de Madrid. ${ }^{12}$ La foto que presentamos muestra la copia que Mariano Pardo de Figueroa, famoso filatélico conocido también bajo el seudónimo de Dr. Thebussem, tenía en su colección de documentos filatélicos y que actualmente se encuentra en el Museo Postal de Madrid. El propio Mariano de Pardo lo describe en uno de sus libros dentro de un largo listado de otros mapas postales. ${ }^{13}$ Desde entonces sólo un autor que ha escrito sobre el tema se ha referido a la existencia de dicho mapa, sin aprovechar apenas la información ahí contenida. ${ }^{14}$

Antes de utilizar datos sacados del mapa sería conveniente preguntarse sobre su fiabilidad o si refleja tan sólo un sueño, una planificación, una utopía en base a un plan por realizar, deseable, pero nunca alcanzado. Podría describir la planeada o proyectada extensión de la red postal carlista del Maestrazgo dentro del territorio bajo su control. En este caso sería la aplicación de las directrices y preceptos que el general Dorregaray publicó en su decreto de 16 de febrero de $1875 .^{15}$ Podría tratarse de un mapa que refleja las conducciones realmente existentes o un mapa de uso oficial, ya que el original es una litografía como reza la nota marginal en su parte superior izquierda.

El diseño del mapa cubre la zona costera entre Valencia y Tortosa, se adentra en su parte superior a la altura de la desembocadura del Ebro hasta Flix desde donde baja en línea casi recta, paralela a la línea costera, hasta Santa Cruz de Moya, ya en la provincia de Cuenca, para llegar desde allí en ángulo recto vía Chelva y Liria hasta su punto de salida.

Nuestro mapa no es el que Dorregaray libró al lanzar el mencionado decreto sobre la reorganización del correo y que lo acompañaba en un principio. ${ }^{16}$ Aquí no se indican ni las conducciones que él establece y manda crear en su decreto. El texto determina con letras y números las diferentes conducciones y sin el mapa que llevaba las correspondientes indicaciones no somos capaces de reconstruirlas. Comparan-

12 Se trata de un fondo sin clasificar $y$, por consiguiente, inaccesible de momento.

13 DE PARDO, M. (1895): Fruslerías postales, Madrid, p. 238.

14 ESCALADA: La organización, p. 56-59.

15 OLIVER: Dorregaray, Anexo, p. 46-47.

16 El mapa referido de Dorregaray que acompañó su decreto no se encuentra en el libro. 


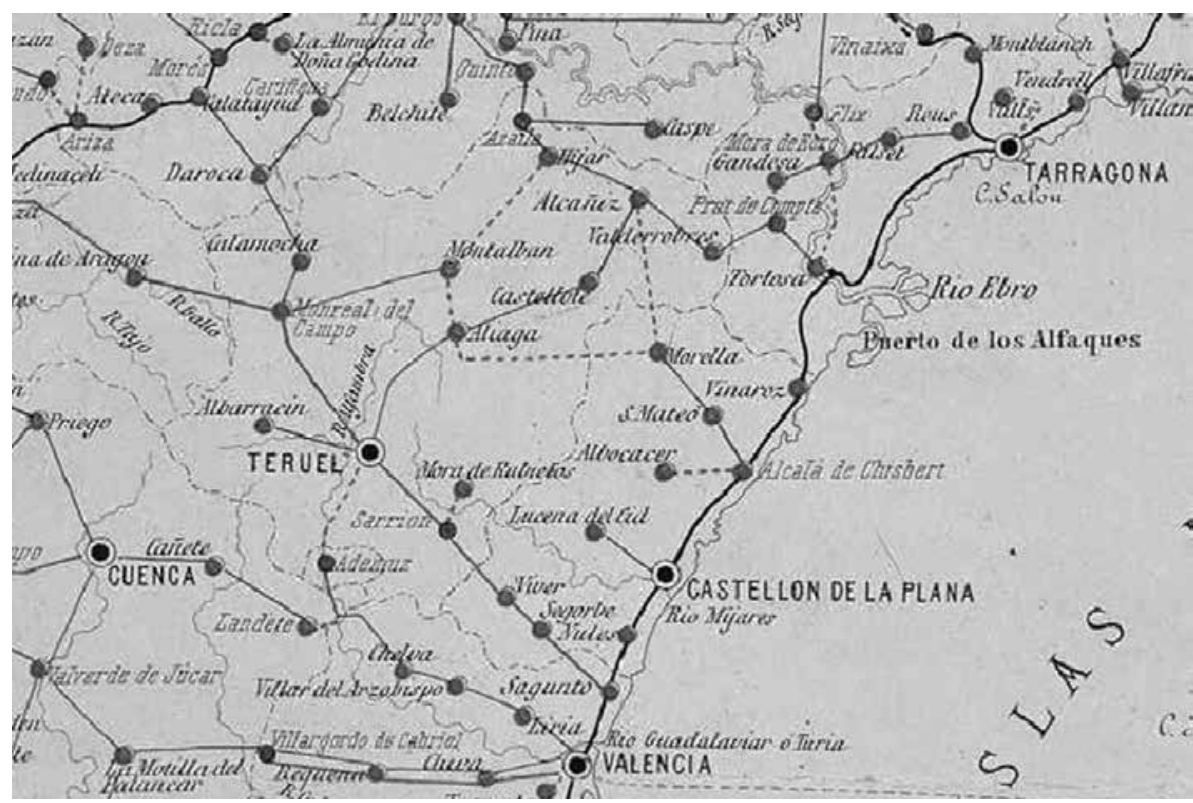

Fig.- 2. Mapa postal. Dirección General de Correos. 1873.

do la relación de los pueblos pertenecientes a las cinco administraciones postales según el proyecto de Dorregaray (Gandesa, San Mateo, Castellón, Segorbe y Chelva) se vislumbra la estructura de la red con sus distintos itinerarios.

Quedan lagunas, sobre todo, porque el mapa no indica en qué pueblos estaban realmente ubicadas las administraciones subalternas, ni siquiera indica la administración central que pudo estar en Vistabella, como dice el mapa, o en la vecina Villahermosa adonde se había trasladado en 1875 la Imprenta Real. También es raro que Dorregaray no mencionara ninguno de estos dos pueblos tan importantes para la infraestructura militar y adminis- trativa carlista ni los incluyera en su esbozo. Pensamos que finalmente, siguiendo la lectura del mapa, se creó otro sexto distrito administrativo postal en la zona turolense por el que trancurría la línea de Santa Cruz de Moya vía Sarrión y Mora de Rubielos a Cantavieja y otra casi paralela de Chelva, Rubielos de Mora y Mosquervela a Cantavieja. De todas formas queda poco claro cuál era el papel real de la administración central de Vistabella o Villahermosa y si el suministro de este supuesto sexto distrito era organizado desde allí.

A pesar de las incertidumbres descritas, el origen del mapa no parece dudoso. Su uso como mapa postal tiene su lógica por el lugar dónde 
fue requisado, concretamente en la administración (¿̇centrale) del correo carlista en Vistabella. También está claro que no se puede tratar de un simple mapa geográfico ni de un mapa militar, ya que el diseño no representa importantes ciudades como Sagunto, Segorbe y Castellón - Teruel ni contiene signos característicos de este tipo de mapas. La ausencia de muchas ciudades tiene su explicación. Dichas ciudades no estuvieron, sino corto tiempo como en el caso de Segorbe, en manos de los carlistas. Otras como Vinaroz o Benicarló están representadas, pero no unidas a la red postal. Las partes extremas (Aliaga y Santa Cruz de Moya) son sitios en donde hubo guarniciones carlistas permanentes. La única excepción a la regla es la conducción de Chelva a Valencia de la que hablaremos más tarde.

Al haber sido el mapa original una litografía, tuvo que ser impreso en el único taller litográfico que existía en toda la zona en guerra, taller del que salió también el sello carlista valenciano. ${ }^{17}$ Asi que es de suponer que en su día existieran más ejemplares, destinados a las administraciones subalternas. El mapa refleja, pues, la situación real del servicio interno del territorio controlado.

\section{EL CORREO CIVIL CARLISTA}

En la primavera de 1874 se crea un servicio postal con sellos propios en Cataluña. La consiguiente reglamentación del servicio tanto por la parte estatal como la carlista marcan el comienzo de una nueva fase para el suministro postal. ${ }^{18}$ Todo ello obligó o a la creación en el Maestrazgo de un servicio propio, o a la reorganización del hasta ahora existente aprovechando, donde se prestaba la oportunidad, la cooperación de los anteriores funcionarios. Esto lo intentó primero el general Palacios desde la zona turolense y luego Alfonso de Borbón Parma, hermano del pretendiente Carlos VII, desde Chelva donde tenía instalado su cuartel general en verano de 1874. Esta localidad se había quedado sin servicio estatal en octubre de 1873, y no se restablecería hasta el final de la guerra en esta zona en el verano de 1875. ${ }^{19}$ No sabemos, sin embargo, cuáles eran las medidas concretas. Cuando hacia finales del año 1874 el pretendiente Carlos VII separó los mandos del ejército de Cataluña y de Valencia, su hermano Alfonso se retiró de Chelva y el general Dorregaray tomó el mando del Ejército del Centro a principios de 1875 . Su

17 Véase la nota marginal del mapa.

18 El Volante de la Guerra, nº 6, p.4 en AHN, PB, Diversos, 116, exp. 2, 27.

19 LLATAS, V. (2014): Efimérides de las Guerras Carlistas en el Villar del Arzobispo, $2^{a}$ ed., Villar del Arzobispo, p. 39. 
análisis de la situación administrativa coincide con el que Alfonso de Borbón había hecho apenas medio año antes, lo que hace pensar que las medidas tomadas hasta la fecha no habían sido muy eficaces en su conjunto o al menos en la parte central y norte del territorio dominado.

En el campo postal Dorregaray desarrolla un plan para la correspondencia y la telegrafía con medidas concretas para la instalación de una línea eléctrica entre los centros militares de Villahermosa y Cantavieja y de una línea óptica desde Flix a Chelva atravesando el territorio de norte a sur, y con ramales hacia Castilla y Aragón, forman parte de él. ${ }^{20} \mathrm{El}$ material, cableado, hilo, aparatos transmisores etc., requisado a propósito a lo largo de la línea férrea de la costa siguiendo las instrucciones oficiales, no era suficiente, y la falta de personal cualificado para ambos sistemas fue finalmente la causa principal por lo que todo se quedó en un intento. ${ }^{21}$

La organización postal llega, sin embargo, mucho más lejos. Según Evarist Olcina "... dentro de sus limi- taciones, [en Cataluña y] en el País Valenciano, llegando a extenderse en 1875 hasta las últimas aldeas". ${ }^{22}$ A falta de datos y citas verificables, este dato tiene que quedar como opinión particular suya.

El plan de Dorregaray preveía una red de peatones que debían desplazarse a diario desde su pueblo base al vecino siguiendo los iterinarios trazados en su decreto. Los pueblos vecinos más pequeños, no suministrados directamente, tenían que encargarse por su propia cuenta de la recogida y entrega de su correspondencia en los pueblos ubicados en las líneas principales.

Nuestro mapa marca solamente los caminos y conexiones entre los pueblos ubicados en dichas líneas, sin más comentarios ni signos, omitiendo los pueblos más o menos pequeños fuera de ese recorrido. Pero no nos permite ver cuáles eran los centros administrativos subalternos o centros de distribución. Ni siquiera Vistabella, supuesto centro administrativo, destaca por ninguna señalización especial. La orientación del sistema de distribución en los centros

21 Algunos autores se confunden de bando cuando hablan de las obras para la instalación de una línea de telegrafía óptica por la parte del Ebro y adjudican la obra, realizada según un proyecto del general Salamanca, al bando carlista. GONZÁLEZ, C., GUAL, V., PARDO, R.: La telegrafía óptica en Castellón [www.aulamilitar.com; 31.5.2016, 11.40] explican la instalación con muchos detalles. 
administrativos militares, propuesta por Dorregaray, no parece haberse realizado sino parcialmente.

\section{LAS CONEXIONES CON EL EXTERIOR}

Uno de los problemas principales que tenía el correo carlista tanto en el Norte, como en Cataluña y el Maestrazgo, estribaba en que se trataba en el fondo de un sistema de conducción de correspondencia inoficial, no reconocido por ningún Estado, ni, por supuesto, por Madrid. Vivía en una burbuja, en una especie de circuito cerrado, que marcaba los límites del comercio y de una correspondencia para la que justo en 1874, durante el Congreso Postal de Berna, las naciones más avanzadas estaban buscando formas y fórmulas para facilitar el intercambio internacional del correo.

En el Norte y en Cataluña el problema del aislamiento internacional se pudo salvar instalando oficinas inoficiales de correo en Bayona y Prats de Molló para Cataluña, toleradas durante algún tiempo por la política francesa. Un Encargado de la correspondencia carlista organizaba la reexpedición de los envíos postales de las zonas carlistas para el extranjero aplicando el franqueo francés oficial. Luego, viéndose obligados a cerrar esta oficina, el así llamado Servicio de Fronteras se encargaría desde Irún de la tarea de encaminar la correspondencia hacia el extranjero. Parece que también en la parte catalana existió una pequeña organización parecida que se encargaba de reexpedir la correspondencia carlista en Perpiñán. ${ }^{23}$

Para enviar correspondencia a la España liberal había que acudir a las oficinas postales de las grandes ciudades que habían quedado en manos del Gobierno. Desde allí militares escoltaban los correos a través del territorio carlista circundante.

En el Maestrazgo no existía frontera con un país extranjero ni había ciudades importantes en manos de los liberales que finalmente conservaran su contacto postal y desde donde se pudiera mandar correspondencia fuera de la zona dominada. Así que uno de los mayores problemas era cómo recibir correspondencia desde fuera del territorio bajo control carlista o incluso desde el extranjero y cómo hacer llegar la correspondencia al exterior. Como zona rural y relativamente pobre, el comercio no tenía tanta importancia como en las otras dos regiones. ${ }^{24}$ Pero, no todos los soldados carlistas venían de la zona del Maestrazgo y de vez en cuando sentían la nece-

23 AHN, PB, Correspondencia 95, exp. 3, n' 378.

24 CARRERAS CANDI, F. (1908): Estudios postales I. Disquisiciones filatélicas y postales, Barcelona, p. 61-67. La tinta para imprimir los sellos de correo tuvo que encargarse en Valencia. 
sidad de dar a sus familias señales de vida.

El problema de la conexión con el exterior se agudizó con la presencia de Don Alfonso y la instalación del cuartel general del Ejército de Valencia en Chelva. Alfonso de Borbón y Austria-Este vino acompañado de su joven esposa Nieves de Braganza. Esta situación obligó a buscar una posibilidad de comunicación tanto para fines oficiales como privados, tanto para ellos como para otros oficiales y acompañantes extranjeros. La nutrida correspondencia con Chelva desde el extranjero que se conserva en el fondo Borbón-Parma demuestra que existía tal necesidad y que, efectivamente, se pudo encontrar una solución: un enlace parecido al existente en el Norte y arriba descrito.

¿Qué perfil debería tener este enlace? Por un lado tuvo que tener la posibilidad de recibir correspondencia desde el extranjero sin que esto llamara la atención de ningún funcionario de Correos. Por otro lado la de recibir visitas y cierta cantidad de correspondencia entregada por personas particulares y forasteras, así como tener la posibilidad de reexpedir cartas, meterlas en buzones $y / o$ entregarlas en una oficina de correos sin llamar la atención de los funcionarios o de otra gente. Ade- más tuvo que poder adquirir cierta cantidad de sellos de correo sin que esto tampoco llamara la atención en los estancos.

Analizando la correspondencia conservada que a todas luces tuvo que tomar el descrito camino, podemos afirmar que el encargado tuvo que ser un comerciante, abogado, notario o un funcionario de algún consulado. El necesario contacto seguro con el extranjero hace pensar en lo último. Entre las tres zonas rebeldes principales no había servicio postal, así que el correo recibido no pudo tomar la vía terrestre a través del Maestrazgo y Cataluña, el saliente tampoco. Además hubiera tardado unas cuatro semanas como mínimo, si nos basamos en un caso concreto de una carta remitida desde la catalana Solsona con destino Biarritz que tuvo que pasar primero por Perpiñán. Tardó 15 días, incluidos los dos desde Perpiñán a su destino final. ${ }^{25}$

El contenido de algunas de las cartas conservadas en el ya citado fondo Borbón-Parma del Archivo Histórico Nacional nos permite conocer algo más sobre el correo. Contiene mucha correspondencia de carácter político-militar dirigida durante la contienda a Don Alfonso de Borbón y Austria-Este tanto desde fuera como desde dentro del 
territorio dominado por los carlistas. Además conserva parte de su correspondencia privada y de la de su esposa que le acompañaba tanto en el teatro de guerra catalán como en el Maestrazgo.

El contacto con Francia se mantenía a través del vicecónsul francés de Benicarló, Juan O'Connor y de un tal Mariano Boix, también vecino de la misma ciudad. ${ }^{26}$ Para el contacto con Austria e Italia el enlace fue, posiblemente, el vicecónsul de Austria-Hungría y de la Santa Sede en Valencia, Francisco Royo Salvador, diputado carlista por Morella y abogado. ${ }^{27}$ Hay que admitir que en el segundo caso no tenemos pruebas concretas que apoyen nuestra suposición que se basa en la búsqueda de personas que cumplieran con el perfil arriba desarrollado.

Con todo, esta vía no podía ser utilizada para el correo normal. Aún a falta de evidencias documentales habrá que pensar, si no en cierta "censura" del correo por funcionarios liberales en puntos como Valencia, Castellón o Reus, en una vigilancia de los envíos con desti- nos "sospechosos" como se había practicado en conflictos anteriores. Aparte de la conducción de la correspondencia privada y oficial del cuartel general estaba la de los soldados y alguna comercial que salía vía Valencia. Si no hubiera existido esta posibilidad, no se habría anunciado de forma oficial en los mapas postales que podemos suponer en las oficinas del correo carlista tanto para la información de los funcionarios como para los usuarios. No sabemos cómo funcionó exactamente, sabemos que había como mínimo dos vías para mantener el contacto con el extranjero dependiendo del país de destino o de procedencia y que probablemente no tenían, por razones de seguridad, el mismo enlace.

¿Cómo debió de funcionar el servicio? Primero no funcionaría de forma regular, sino ocasional. Un peatón-cartero carlista saldría desde el cuartel general de Chelva y entregaría y recogería en Valencia los sobres con la correspondencia saliente y entrante. Por el aislamiento de la zona la correspondencia comercial

$26 \mathrm{AHN}, \mathrm{BP}$, Correspondencia 95, exp. 3, n० 115-117.

27 Royo asistió al Congreso de Vevey, junta de los carlistas exiliados, donde se acordaron los preparativos para la insurrección. El Vizconde de la Esperanza: La Bandera Carlista en 1871. Madrid 1871, p. 37-45. DEL BURGO, J. (1994): Carlos VII y su tiempo, Pamplona. Parece que se puede excluir que el vicecónsul de Alemania y Suecia en Valencia, el sueco (i!) Harald Johann Dahlander, (también) estuviera implicado. Igual que su pariente Karl Adolf, vicecónsul en Alicante $\mathrm{y}$ "ardiente defensor de la fe luterana", guardaba seguramente pocas simpatías por el carlismo. VILAR, J.B. (1994): Intolerancia y libertad en la España contemporánea, Madrid, p. 252. 
debió de ser mínima. La privada de los soldados solía ser unidireccional. Además se evitaría en lo posible el envío de correo hacia la zona rebelde desde España para proteger esta vía de comunicación y para no revelar el punto de entrega y su enlace.

El Volante de la Guerra, periódico de campaña y en un principio también boletín oficial carlista para la zona del Centro, señala Chelva como sede del Encargado del Correo Carlista. ${ }^{28}$ La correspondencia hacia el extrior debía de llegarle en sobre doble. El sobre exterior llevaba la dirección del encargado. Dentro iban la carta y uno o varios sellos carlistas sueltos, según el peso de la carta, a modo de pago. El encargado franqueaba las cartas con sellos liberales y las entregaba al cartero que las llevaría a los enlaces en territorio liberal, encargados de echar las cartas a diferentes buzones o entregarlas en pequeño número en una o varias oficinas.

El mapa postal carlista marca dos líneas que salen de dicho territorio: una desde Chelva vía Liria a Valencia y otra hacia Aliaga (desde Vistabella o Villahermosa); posiblemente habría un tercer enlace vía Santa Cruz de Moya y Ademuz.

\section{El mito del "sello mellizo"}

Una administración postal moderna necesita sellos de correo propios. Son una fuente de ingresos verifica- ble para las arcas públicas además de medio de propaganda. Siguiendo los ejemplos del País Vasco, Navarra y Cataluña, también para el Centro se diseñó e imprimió un sello propio que se puso en circulación antes del verano de 1874 . Lo particular de esta emisión es que no existe ningún documento oficial carlista que nos confirme la fecha de su puesta en circulación ni que nos certifique su diseño exacto.

Si consultamos los catálogos de sellos actuales sobre los sellos carlistas de Valencia, nos encontramos bajo el apartado de la Guerra Carlista, con una información que realmente debiera de sorprender hasta a los filatélicos que se consideran medianamente críticos. Con el número 159 no se nos presenta un sello, sino dos. Ambos tienen el mismo dibujo. Sobre un fondo de líneas radiales se ve en un óvalo central el busto del pretendiente al trono, Carlos VII, sobre líneas horizontales, mirando hacia su izquierda. El óvalo está flanqueado por dos lises borbónicas. Dos banderolas, con la leyenda "España Valencia" arriba y "Correos 1 12 Real" abajo, se interponen entre el óvalo y los marcos inferior y superior del sello. Se trata de una litografía en color rojo.

Es obvio que las diferencias del diseño no pueden ser casuales, debidas a defectos del cliché o del reporte, de desgaste u otras razones pare- 

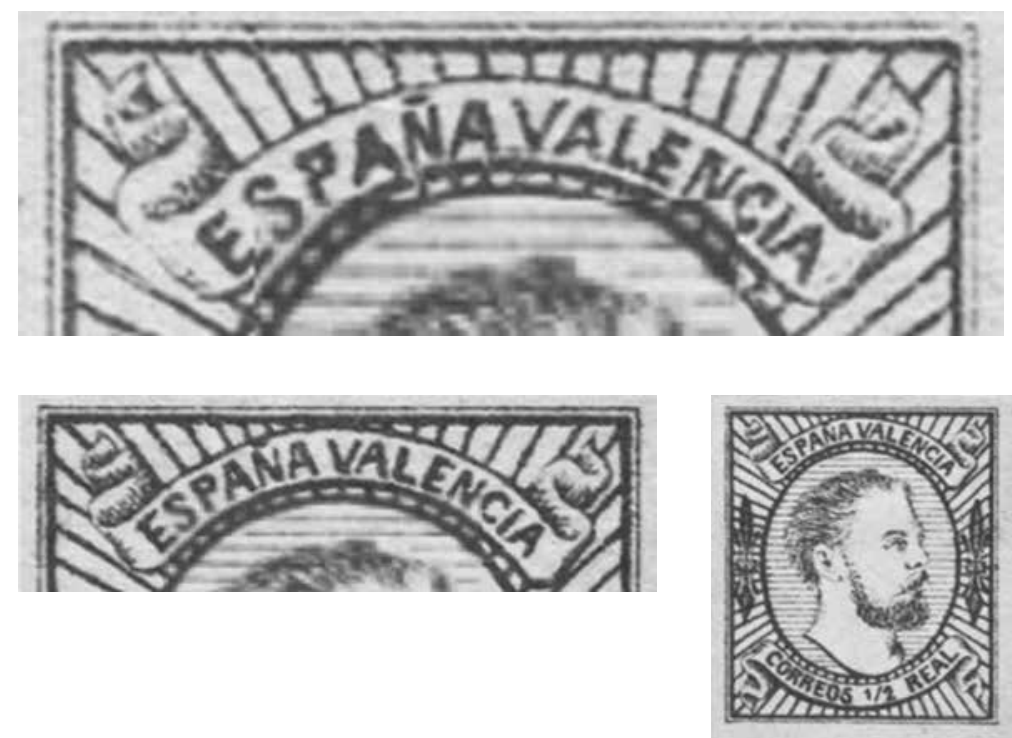

Fig.- 3. El "sello mellizo". (Detalles). Catálogo Gálvez, 1960.

cidas. Se deben, supuestamente, a la voluntad creadora de su grabador, Juan Vilás, ex-oficial carlista y responsable del taller litográfico de Vistabella, luego trasladado a Villahermosa, la única que había en todo el territorio dominado por los carlistas del Maestrazgo.

Las diferencias entre las dos versiones del sello consisten en el diferente número de líneas de fondo horizontales, en la colocación de la banderola superior que toca 0 no toca el marco del sello y la diferente colocación de las cifras del valor, más centrado o más pegado a la palabra "Real", según el tipo. Los sellos se encuentran en oposición vertical con su "hermano mellizo" de la fila anterior en cada una de las filas de la piedra litográfica original con la que se imprimieron.

El hecho de la existencia de un "se"lo mellizo" en sí, del mismo color y del mismo valor, es algo nuevo o al menos novedoso, hasta la fecha nunca visto y merecería ya de por sí un sitio señalado dentro de la historia postal y filatélica de España. Si tenemos en cuenta las dificultades a las que tenía que enfrentarse su creador a la hora de diseñar su obra y grabarla, todavía se torna más meritorio este esfuerzo. ${ }^{29}$ Pero 
a pesar de esto, esta original creación no parece merecer ni necesitar ninguna explicación más en el citado catálogo. Tampoco en otras publicaciones se encuentra explicación alguna, tan sólo se constata el mero hecho de su existencia.

Es, sin embargo, un hecho desconcertante que ni los mismos filatélicos, coleccionistas, comerciantes y expertos se pongan de acuerdo sobre cuál de las diferentes versiones de parejas verticales del sello valenciano ofrecidos en el mercado filatélico es la auténtica. Hay varias y se distinguen, entre otras cosas más difíciles de detectar, por el número diferente de líneas de fondo del óvalo central del primero de los dos sellos, que el catálogo llama tipo I. El holandés Hans Vinkenborg fue el primero en poner el dedo en la llaga, sin ir, desgraciadamente, al fondo de la cuestión. ${ }^{30}$ La discrepancia existente sobre el número de líneas de fondo del ejemplar auténtico no permite más que llegar a la única explicación lógica de que algunos de estos ejemplares tienen que ser a la fuerza falsificaciones.

Aquí no vamos a intentar determinar cuál es, o cuáles son, los sellos auténticos porque creemos poder demostrar a continuación, como ya reza el título de este capítulo, que la idea del "sello mellizo" es una falsedad convertida en mito. A su propagación contribuyó, y no poco, el prestigio de Jean-Baptiste Moens, editor de la revista belga Le Timbre Poste comerciante filatélico y autor de más de una decena de libros, considerado por muchos el "padre de la filatelia europea". En España, cuna del presunto "sello mellizo", es el filatélico, abogado e historiador Francisco Carreras Candi quien, al no ser comerciante, tenía y sigue teniendo prestigio dentro del mundo de la filatelia y era poco sospechoso de defender con sus tesis intereses comerciales. Además fue el primero y único en ahondar en la cuestión. Aunque luego aparecieran opiniones diferentes a la suya, nadie se ha atrevido públicamente a poner en tela de juicio sus conclusiones, someterlas a un examen crítico o incluso contradecirlas. Parece casi inevitable pensar que los motivos para tan escasa voluntad crítica fueran económicos y comerciales.

Para salir de dudas no nos queda otra alternativa que someter lo publicado por Carreras Candi a un examen crítico. Más de 30 años después de la creación del sello carlista valenciano, el historiador catalán nos presenta en su libro Disquisiciones la historia de todos los sellos carlistas, acudiendo para los de Valencia incluso al testimonio de su creador. El libro, que incluye partes importantes de la entrevista, nos presenta al final también una lámina con ilustraciones de dichos

30 VINKENBORG, H.: De Carlistenzegel vit Valencia, Iberia 100, p.50-57. 
sellos. Lo que a primera vista parece tarea fácil, no lo es.

El capítulo del libro que habla del correo carlista del Maestrazgo se titula "Centro 1874". A modo de subíndice enumera los temas que tratará. Los tres primeros son: "Sello de correos emitido para el Centro en 1874. -Sus dos variedades.Falsificaciones del mismo". La enumeración incita ya a una todavía leve sospecha de que hay algo raro entre la presentación del sello y el relato del grabador que viene después. La primera frase después de la presentación del sello, dedicada a introducir este testimonio, confirma nuestro principio de sospecha ya que empieza: "Conocido ya el sello emitido para uso de los pueblos que el ejército carlista ocupaba..."

El autor nos acaba de presentar el sello valenciano como "sello mellizo" y ha establecido cuáles son sus dos falsificaciones. Su referencia más importante es Jean-Baptiste Moens quien había descrito en dos artículos de diciembre de 1874 y junio de 1875 cuatro diferentes sellos carlistas del Centro que le habían sido presentados y del que, como mínimo, uno había estado en circulación, aunque, presuntamente, como falso postal, o sea un ejemplar para engañar a la administración postal y no a coleccionistas. ${ }^{31}$ La afirmación de Carreras al presentar los falsos de que, según Moens, dichos sellos "son reconocidas imitaciones que a pesar del origen más o menos auténtico que a veces se les ha atribuido [...] comenzaron a circular entre los coleccionistas" es gratuita ya que ni uno ni el otro pueden presentar ninguna prueba. Es más, la historia que cuenta Moens, según la cual el general carlista Marco de Bello estaba implicado directamente en la falsificación de uno de dichos sellos que incluso ya había circulado como falso postal, pone en tela de juicio la fiabilidad de la información recibida y difundida por el belga, ${ }^{32}$ quien, por cierto, fue uno de los que se encargaron de su circulación filatélica al ofertarlos en su propia revista. ${ }^{33}$

Pero volvamos al texto. El hecho de que un sello presuntamente autén-

31 LANG-VALCHS, G. (2016): ¿̇Falso filatélico o falso postalę, Eco Filatélico y Numismático n 1248, pág. 24-25.

32 Moens cuenta incluso más tarde que Marco de Bello fue acusado y juzgado por la falsifiacción de dicho sello y castigado con una pena de cárcel por haber sido considerado autor del fraude. Un completo despropósito. TP, n 293, mayo 1887, p. 54.

$33 \mathrm{TP}, \mathrm{n}^{\circ} 150$, p. 48. 
tico exista en pareja "melliza" se afirma sin más. La fuente de esta información, que no nombra, es una escueta nota de febrero de 1875 en la revista de Moens que no solamente no da ninguna explicación adicional, sino que tampoco se completa, como se podía esperar, con una ilustración de tan singular ejemplar. En ningún número de su revista Moens es capaz de presentar una pareja vertical de este sello aunque volverá a tratar este tema en varios artículos posteriores. ${ }^{34} \mathrm{~A}$ pesar de lo que Carreras anuncia, su lámina sí presenta dos sellos de $1 / 2$ Real diferentes, pero tampoco puede presentar una pareja vertical. A cambio presenta una pareja horizontal con un presunto matasellos carlista. ${ }^{35}$

A continuación de la presentación reproduce al pie de la letra el relato del litógrafo Juan Vilás que, por lo visto, Carreras anotó en su día y que contiene "algunos datos, en estremo curiosos, relativos a su confección". $O$ sea, Carreras no tiene ninguna duda sobre el diseño del sello, aunque no ha traído ningún ejemplar, no hace ninguna pregunta específica ni sobre su diseño, ni el por qué de su duplicidad, ni sobre la fecha de puesta en circulación. ${ }^{36}$

Este comportamiento, casi desinteresado y pasivo, cambiará sustancialmente en la segunda parte de la entrevista. Ahora toca hablar del asíllamado sello de Cantavieja, un segundo sello valenciano, supuestamente creado en los últimos días de la guerra en el Maestrazgo. El interés del autor en este tema se nota enseguida. Ha concertado la entrevista con el litógrafo para hablar con él sobre este sello y disipar las dudas que tenía. Ha traído una copia o incluso un ejemplar de este y hace preguntas muy precisas para aclarar las circunstancias de su creación. Vilás, tras admitir que había diseñado otros timbres fiscales, dice no haber visto nunca este sello, ni litografiado ni en tinta, y niega haberlo creado o participado en su creación. En estas afirmaciones

34 En ninguno de los muchos catálogos de sellos españoles o extranjeros, en ninguna otra revista (filatélica) ni en ninguno de los libros que publican algo sobre este caso hasta principios del siglo XX se encuentra una ilustración, copia o foto de los "mellizos".

35 Este sello en tinta debe ser un falsificación. No se corresponde con ninguno de los sellos y encabezamientos que se encuentran en los documentos y la correspondencia carlistas.

36 En el subíndice habla de marzo, pero con una interrogación. 
se basa Carreras para llegar a la conclusión en este caso, a nuestro juicio correcta, de que tal sello es una falsificación. ${ }^{37}$

Después de haber analizado aunque tan sólo someramente la presentación de ambos sellos por Carreras Candi en su libro, no debiera extrañar la sospecha que expresamos y la primera impresión que tuvimos ya al leer el subíndice. El relato de $\mathrm{Vi}$ lás es, para Carreras, mero adorno, un apéndice de su presentación. Ninguna de las informaciones allí contenidas es aprovechada ni para contrastar ni para apoyar su preestablecida opinión sobre los auténticos sellos valencianos, basada en las afirmaciones de Moens. Como veremos en el siguiente análisis detallado del relato del grabador, Vilás, sin contestar preguntas sobre el tema que nos preocupa, deja en evidencia a su interlocutor.

Primero Vilás relata las condiciones de trabajo en su improvisado taller que son bastante precarias y sus herramientas rudimentarias. Instalado primero en una finca de las inmediaciones de Vistabella no dispone ni de silla ni de mesa de trabajo. De buril le sirve una aguja de coser fijada en un palito de madera, el busto del pretendiente lo tiene que grabar sin tener ni una foto o retrato de Don Carlos.

Vilás cuenta también que tuvo problemas para conseguir la tinta. Habla de un solo tiraje y parece haberse tenido que contentar con una tinta y un solo color. El sello se imprimió con una tirada única de 200.000 ejemplares en pliegos de 104 sellos, o sea unos 2000 pliegos. No da ninguna fecha concreta de la terminación del trabajo.

Cuando se refiere a su obra, Vilás siempre habla en singular, habla en repetidas ocasiones de "el sello grabado por mí", del "tan conocido sello carlista de Valencia", de la "confección del sello de correos". ${ }^{38}$ No satisfecho con el resultado de su trabajo, se dispone, una vez cambiado y reorganizado su taller en Villahermosa, a preparar una nueva edición bajo mejores condiciones, sobre todo contando ahora con un retrato del pretendiente. Entonces graba "dos sellos de correos,

37 Moens tenía este sello por falso. Algún catálogo español, sin embargo, lo daba por bueno. José María Sempere demuestra en varios artículos la inconsistencia de la argumentación que pretende defender su autenticidad. Véase SEMPERE, J.M.: A vueltas con el 3 cuartos carlista y El 3 cuartos carlista de Cataluña. Un sello fantasma. [http://www.filateliadigital.com/a-vueltas-con-el-3-cuartos-carlista/; $31.5 .2016,10.33$ y [http://www.filateliadigital.com/el-3-cuartos-carlista-de-cataluna/; $31.5 .2016,10.37]$.

38 CANDI: Disquisiciones, pág. 63. 
para reemplazar, en el año 1875, al que circulaba desde el año anterior". ${ }^{39}$ Pero ya no puede "proceder al nuevo trabajo" porque tiene que huir con la tropa ante el acoso del ejécito liberal.

Queda bastante claro que el creador habla durante la entrevista de un sólo sello. A este hecho se suma la imposibilidad de encontrar durante treinta años ni un solo ejemplar del pretendido "sello mellizo", ni una sola ilustración o foto de este conjunto que no aparecería publicado hasta bien entrado el siglo XX.40 Ninguna de las parejas (verticales) presentadas hasta el día de hoy como candidatos auténticos cumple los criterios que ofrecen las descripciones del (supuesto) fenómeno en la revista Le Timbre-Poste y en un estudio publicado en 1879 por la Royal Philatelic Society de Londres. ${ }^{41}$

En el caso de la revista belga la descripción de los dos ejemplares sueltos, no unidos, que supuestamente componen el conjunto, es anterior a la noticia de su supuesta particular posición en la misma plancha. ${ }^{42} \mathrm{En}$ el caso de la publicación inglesa se comenta la (supuesta) posición en la plancha además de la existencia de una línea fina de separación entre ambos, sin que quede claro si estas informaciones se basan en la observación y descripción directa de dicho fenómeno de una pareja vertical real y presente o si se trata simplemente de la repetición de la información sacada de la revista de Moens mezclado con la noticia de The Philatelist sobre una línea separatoria. ${ }^{43}$

Teniendo en cuenta todo esto no queda más remedio que relegar la idea de un "sello mellizo" al campo de la fantasía y de la mitología filatélica.

Llegados a este punto se impone la pregunta: ¿Cuál es, pues, el auténtico sello carlista valenciano? Este tema, sin embargo, es más compli-

39 Ibidem, pág. 65.

40 Friederich, primero en ilustrar con fotografías una publicación que incluye nuestros sellos, sólo puede presentar ejemplares sueltos. FRIEDERICH, R. (1894): Die Postwertzeichen Spaniens und seiner Kolonien", $2^{a}$ edición, Berlin, lámina X.

41 El diferente número de líneas de fondo horizontales y el número de líneas entre la cabeza y la parte superior del óvalo para Le Timbre Poste se complementan por el estudio británico con un recuento del número de líneas radiales que tocan el marco del sello por la parte interior, diferente también en cada lado, ofreciendo así una serie de criterios difícilmente contestables. Royal Philatelic Society: Catalogue of Postage Stamps, Stamped Envelopes and Post Cards, Spain and Colonies (1879), London, p. 30.

42 TP, $n^{\circ} 144$, dic 1874 , p. 89 y n 145 , ene 1875 , p. 5.

43 The Philatelist (1874), p. 161 (Recent and Undescribed Emissions. Spain) habla de un solo sello. 
cado de lo que parece, necesita de un enfoque filatélico y merece un estudio y análisis tan rigurosos como el aquí presentado. Dicho esto queda claro que tal tarea no tiene cabida dentro del marco de este artículo, la cantidad de información desbordaría los límites sensatos de un artículo y aburriría al lector. Este tema será tratado en otro artículo o librito de próxima publicación.

\section{Distritos postales Carlistas segúN el DeCreto de Dorregaray}

Gandesa:

+Alfara; +Arnes; +Ascó; +Beceite; Benisanet; Bot; Castellfort; +Cherta; Cinctorres; Corvera: Fatarella; +Flix; Forcall; +Fuentespalda; Hervés; Horta; Hortells [Ortells]; La Mata; +Miravet; +Peñarroya; Pinell; +Roquetes; +Santa Bárbara; +Torre de Arcos; +Valderrobres; Vilafranca del Cid; Zorita

\section{San Mateo:}

Aldover; Ares del Maestre; Vallestar; Canet lo Roig; Catí; +Cervera del Mestre; +Chert; +La Senia; Mas de Barberans; Pobla de Benifasá; Regués; Rosell; Salsadella; +Santa Magdalena; Sierra Engarcerán; *Tirig

Vallibona

Segorbe:

Alcudia de Veo; +Aljimia; *Argelita; +Artesa; Barracas; +Cau- diel; El Toro; *Espadilla; +Eslida; Gaibiel; Mater; +Montán; +Onda; Pavias; Pina; Puebla de Arenoso

Chelva:

Alpuente; +Arcos; Aras de los Olmos (Alpuente); *Calles; ${ }^{*} \mathrm{Ca}$ nales; ${ }^{*}$ Casas Bajas; La Yesa; La Cruz de Moya; Titaguas; *Tuéjar; +Abejuela; +Andilla; +Begis; +Líria; +Losa; +Torrijas; + Villar del Arzobispo

Castellón:

+Albocácer; +Alcalá de Chisvert; +Alcora; +Adzaneta; Artana; Ayódar; +Benafigós; +Benasal; Benlloch; Cabanes; Castillo de Villamalefa; +Certes de Arenosa; *Chodos; +Cirat; +Cuevas de Vinromá; Culla; +Fansara; Figueroles; +Lucena; Ribesalbes; Tales; +Torreblanca; Torre Endomenech; +Oropesa; Useres; +Vallat; Villafamés; +Zucaina

\section{Vistabella**:}

+Alcalá de la Selva; +Aliaga; +Alventosa; +Arbejuela; +Cantavieja; +Cañada de Benatanduz; +Fortanete; +Linares; +Manzanera; +Mirambel; +Mora de Rubielos; +Mosqueruela; +Puertomingalvez; +Rubielos de Mora; +Sarrión; +Torroya

** Este distrito, no presente en el proyecto de Dorregaray, pudo haber sido administrado también desde $\mathrm{Vi}$ - 
llahermosa. No queda claro cuáles eran los pueblos dependientes de la administración central, ni si ésta cambió su sede y estaba finalmente ubicada en Villahermosa. Es probable que en algún que otro caso la aquí propuesta pertenencia de ciertos pueblos, que solamente están presentes en el mapa carlista, a un distrito postal, basada en criterios geográficos y subjetivos del autor, esté equivocada.

* pueblo que no aparece en el mapa carlista

+ pueblo que aparece en el mapa, pero no en el proyecto de Dorregaray

\section{Fuentes}

Archivo Histórico Nacional (Madrid), Fondo de la familia Borbón-Parma.

Museo Postal (Madrid), Legado Thebussem

Le Timbre-poste [TP]

El Volante de la Guerra

The Philatelist

\section{Biblografía}

BAUTISTA VILAR, J. (1994): Intolerancia y libertad en la España contemporánea, Madrid.

CARRERAS CANDI, F. (1908): Estudios postales I. Disquisiciones filatélicas y postales, Barcelona.

CUERPO del Estado Mayor del Ejército (1889) Narración de la Guerra Carlista de 1869 a 1876, tomo XIV, Madrid.

DE PARDO FIGUEROA, M. (1895): Fruslerías postales, Madrid.
DEL BURGO, J. (1966): Bibliografía de las Guerras Carlistas y de las luchas políticas del siglo XIX, Pamplona.

DEL BURGO, J. (1994): Carlos VII y su tiempo, Pamplona.

ESCALADA-GOICOECHEA,E. (2000): La organización del correo carlista (1873.1876), Academia Hispánica de Filatelia, Madrid.

IGLESIAS BALDEÓN, L. (20082009): Numismática y filatelia del carlismo, Boletín de Estudios Históricos sobre San Sebastián, $n^{\circ} 42$ [Separata], San Sebastián.

LANG-VALCHS, G. (2016): ¿̇Falso filatélico o falso postal?, Eco Filatélico y Numismático n 1248, pág. 24-25.

LECLERCQ, A., Waroquiers, G. (1981): Jean-Baptiste Moens 1833-1900, Père de la Philatélie, Bruxelles.

LLATAS BURGOS, V. (2014): Efimérides de las Guerras Carlistas en el Villar del Arzobispo, $2^{a}$ ed., Villar del Arzobispo.

MEMORIA presentada el 2 de enero de 1874 a las Cortes Constituyentes por el ministro de la Gobernación D. Eleuterio Maisonnave, (1874) Imprenta Nacional, Madrid. OLCINA, E. (1974): El Carlismo y las autonomías regionales, Seminarios y Ediciones.

OLIVER, A. (1876): Dorregaray y la traición del centro: Apuntes para la historia de la última guerra civil, Bayona. PEÑA ARTERO, J. (2005): Los sellos carlistas de Cataluña. Contexto histórico, Colección: Monografías Filatélicas de Afinet $n^{\circ} 7$, Barcelona. 
ROYAL Philatelic Society (1879): SEMPERE LUQUE, J. M. María: El Catalogue of Postage Stamps, 3 cuartos carlista de Cataluña. Stamped Envelopes and Post Cards, [http://www.filateliadigital.com/ Spain and Colonies, Londres.

SEMPERE LUQUE, J. M.: A vueltas con el 3 cuartos carlista y El 3 cuartos carlista de Cataluña. Un sello fantasma. [http://www.filateliadigital.com/a-vueltas-con-el-3-cuartosel-3-cuartos-carlista-de-cataluna/; 31.5.2016, 10.37].

VINKENBORG, H.: De Carlistenzegel vit Valencia, Iberia, $\mathrm{n}^{\circ} 100, \mathrm{p}$. 50-57.

carlista/; $31.5 .2016,10.33$ ] 